Review Article

\title{
The Link between Depression and Chronic Pain: Neural Mechanisms in the Brain
}

\author{
Jiyao Sheng, ${ }^{1}$ Shui Liu, ${ }^{1}$ Yicun Wang, ${ }^{2}$ Ranji Cui, ${ }^{1}$ and Xuewen Zhang $^{1}$ \\ ${ }^{1}$ Jilin Provincial Key Laboratory on Molecular and Chemical Genetic, The Second Hospital of Jilin University, 218 Ziqiang Street, \\ Changchun 130041, China \\ ${ }^{2}$ Department of Genetics and Comprehensive Cancer Center, University of Alabama at Birmingham, Birmingham, AL 35294, USA
}

Correspondence should be addressed to Ranji Cui; cuiranji@jlu.edu.cn and Xuewen Zhang; zhangxw@jlu.edu.cn

Received 25 March 2017; Revised 4 May 2017; Accepted 24 May 2017; Published 19 June 2017

Academic Editor: Aijun Li

Copyright (c) 2017 Jiyao Sheng et al. This is an open access article distributed under the Creative Commons Attribution License, which permits unrestricted use, distribution, and reproduction in any medium, provided the original work is properly cited.

Chronic pain, as a stress state, is one of the critical factors for determining depression, and their coexistence tends to further aggravate the severity of both disorders. Unfortunately, their association remains unclear, which creates a bottleneck problem for managing chronic pain-induced depression. In recent years, studies have found considerable overlaps between pain- and depression-induced neuroplasticity changes and neurobiological mechanism changes. Such overlaps are vital to facilitating the occurrence and development of chronic pain and chronic pain-induced depression. In this review, we summarized the role of neuroplasticity in the occurrence and development of the two disorders in question and explored individualized application strategies of analgesic drugs and antidepressants that have different pharmacological effects in the treatment of chronic paininduced depression. Therefore, this review may provide new insights into the understanding of association between chronic pain and depression.

\section{Introduction}

Chronic pain is usually defined as any persistent or intermittent pain that lasts more than 3 months, which can be categorized along a variety of dimensions, including one of the most important divisions, neuropathic versus nociceptive pain $[1,2]$. Neuropathic pain is induced by a lesion or disease involving the nervous system [3], and nociceptive pain occurs as a consequence of actual or threatened damage to nonneural tissue [4]. Chronic pain is a major public health problem, with epidemiological studies reporting that in the USA and Europe, approximately one fifth of the general population are affected [5]. Additionally, as one of the most common and disabling mental disorders, depression has been reported to be the third leading contributor to the global disease burden $[6,7]$. Clinical studies have revealed that chronic pain, as a stress state, often induced depression [8-10] and that up to $85 \%$ of patients with chronic pain are affected by severe depression $[11,12]$. Patients suffering from chronic pain-induced depression exhibit a poorer prognosis than those with chronic pain only; and chronic pain and depression are closely correlated in terms of occurrence and development and are able to mutually promote their own severity progress [13].

To date, neither the corresponding pathophysiological mechanisms of chronic pain and depression nor their mutual correlation has been identified, which poses a huge challenge for the treatment of pain accompanied by depression. However, in recent years, studies have revealed considerable overlaps between pain- and depression-induced neuroplasticity changes and neurobiological mechanism changes. Such overlaps are vital to facilitating the occurrence and development of chronic pain-induced depression. In particular, injury sensory pathways of body pains have been shown to share the same brain regions involved in mood management, including the insular cortex, prefrontal cortex, anterior cingulate, thalamus, hippocampus, and amygdala, which form a histological structural foundation for the coexistence of pain and depression [14]. Furthermore, the volumes of the prefrontal cortex (PFC) and hippocampus have been reported in many studies to be significantly smaller in depressed patients and to be closely related to depression severity [15-17]. In addition, 
individuals with depression in postmortem studies have also been observed to have a significantly reduced number of PFC synapses, which thus decreases synaptic functions [18]. Meanwhile, the effect of PFC on pain development via the nucleus accumbens has also been verified [19], thus indicating that the occurrence and development of pain and depression may be associated with some identical neuroplasticity changes. Furthermore, maladaptive plasticity changes, which refer to the plasticity in the nervous system that leads to a disruption of the function and may be considered a disease state, have also been indicated in a large number of clinical trials and animal studies [20]. Additionally, these maladaptive plasticity changes may also occur in sensory conduction pathways from the peripheral to the central nervous system and participate in the occurrence, development, and maintenance of chronic pain [3]. In summary, chronic pain and depression may be based on common neuroplasticity mechanism changes, which are a potentially important route for the onset and aggravation of chronic pain and depression. Reviewing the role of neuroplasticity in chronic pain and depression, this paper explores the influence of analgesic drugs and antidepressants with different pharmacological effects on neuroplasticity as well as their contribution to individualized application strategies in the treatment of chronic pain-induced depression.

\section{Molecular Mechanisms Associated with Chronic Pain and Depression-Induced Neural Plasticity Changes}

2.1. Monoamine Neurotransmitters. Monoamine neurotransmitters, including serotonin (5-HT), dopamine (DA), and norepinephrine (NE), have been studied in molecular mechanisms involved in chronic pain and depression. The classical monoamine hypothesis proposes that depression may occur as a result of decreased availability of monoamine neurotransmitters such as 5-HT and NE in the central nervous system (CNS) [21], which is supported by strong evidence from many studies [22-24]. Monoamine neurotransmitters are also vital to the occurrence and development of pain. Additionally, electrical stimulation either in the periaqueductal gray or in the rostral ventrolateral medulla may elevate NE levels in cerebrospinal fluid and thus achieve an analgesic effect, which in turn can be blocked by spinal adrenergic antagonists [25].

In exploring the common neuroplasticity changes of chronic pain and depression, attention should also be paid to the midbrain dopaminergic system because it exerts an indispensable role in the control of forebrain functions. In fact, chronic pain has been shown to have the potential to significantly damage DA activity in the limbic midbrain area according to a large body of evidence [26]. The reactivity of the DA system in the limbic midbrain area to significant stimuli has been observed in imaging studies to be reduced in patients with chronic pain $[27,28]$. In particular, the DA receptor $\mathrm{D} 2$, also known as $\mathrm{D} 2 \mathrm{R}$, is a protein that is known to be involved in the occurrence and development of depression [29]. Reduced overall DA levels and significantly lowered D2R expression were found in Sagheddu et al.'s chronic neuropathic pain rat model [30], which provides possible new neuroplasticity targets for the treatment of chronic pain-induced depression.

2.2. Brain-Derived Neurotrophic Factor (BDNF). As a precursor protein, pro-BDNF can be processed into a mature BDNF through intracellular and/or extracellular proteases [31]. BDNF belongs to the family of neurotrophic factors and is not only involved in the signaling pathways of the PFC and hippocampal dentate gyrus together with its receptor tropomyosin receptor kinase $\mathrm{B}(\operatorname{TrkB})$ but is also important in regulating neuroplasticity $[32,33]$. Aside from decreasing BDNF expression and function in the PFC, the hippocampus, and other depression-related structures, depression has been found to reduce the blood BDNF levels in affected patients [34-36]. The crucial function of BNDF in pain occurrence and development has also been confirmed by extensive studies. In particular, Yajima et al. found that BDNF released from the spinal cord can form signaling pathways by binding to $\operatorname{TrkB}$, thereby activating the expression of spinal protein kinase $C$ in spinal neurons, which can regulate hypersensitivity to pain and further influence the progression of neuropathic pain $[37,38]$.

2.3. Inflammatory Factors. The association between inflammatory factors and the CNS has become increasingly clear in recent decades. The surrounding inflammatory response has been shown to cause pain and depression; thus, inflammatory response-mediated pain may be more strongly associated with depression [39-41]. By affecting depressionrelated pathophysiological functional areas via the bloodbrain barrier, inflammatory signals can induce changes in neurotransmitter metabolism, neuroendocrine function, and neuroplasticity [40]. Additionally, the depressive symptoms of affected patients receiving systemic treatment for malignant melanoma or hepatitis $\mathrm{C}$ virus infection with INF- $\alpha$ have been found to be aggravated in several studies, where major depressive disorder (MDD) was clinically diagnosed in up to $45 \%$ of sufferers [42-45]. Furthermore, a high ratio of plasma kynurenine and tryptophan in patients undergoing IFN- $\alpha$ therapy has been shown to predict depression severity $[42,46,47]$.

2.4. Glutamate and Its Receptor Subtypes. Glutamate functions as one of the main excitatory neurotransmitters in the CNS and exists in synapses throughout the brain [48]. Furthermore, glutamate and its receptor subtypes, N-methyl$\mathrm{D}$-aspartic acid (NMDA) receptor and $\alpha$-amino-3-hydroxy5-methyl-4-isoxazolepropionic acid (AMPA) receptor, have been found to be involved in the occurrence and development of chronic pain and depression [49-51]. In the spinal cord, both increased excitatory system activity and the accompanying reduced inhibitory system are known to contribute to central hyperalgesia and to ultimately lead to the progression of pathological pain [52]. Glutamatergic activity can be promoted through the breakdown of efficient inhibition of the actions of glutamate by GABA. GABAergic transmission is excitatory during fetal early 


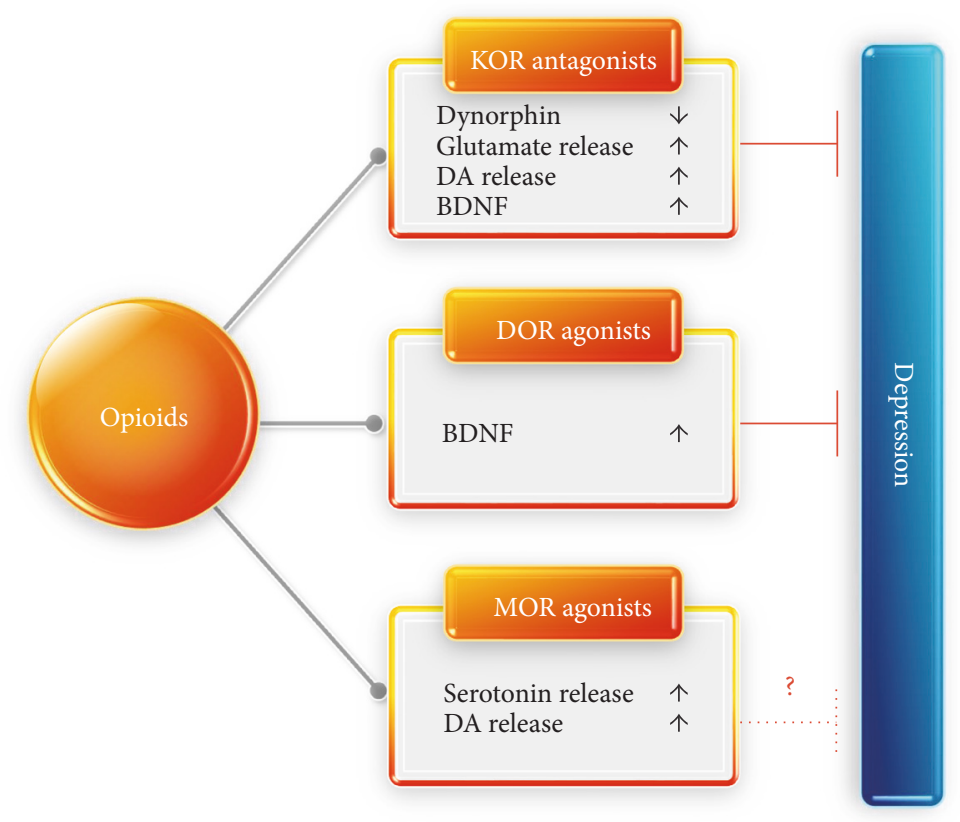

FIgURE 1: Potential mechanisms of opioids in chronic pain-induced depression therapy.

development but becomes inhibitory during late pregnancy, which results from the depolarization caused by the dominance of Na-K-Cl-cotransporter-1 (NKCC1) and $\mathrm{K}-\mathrm{Cl}$-cotransporter-2 (KCC2), which are proteins that aid in the active transport of sodium, potassium, and chloride into and out of cells during early fetal development. Similarly, the return of NKCC1 and KCC2 levels to those of the immature state under pathological conditions increases the excitability of GABAergic transmission, thereby weakening the inhibitory effect [53,54]. Low-dose diazepam (an NKCC1 inhibitor) was administered to the unipolar depression genetic model in Flinders Sensitive Line (FSL) rats in Matrisciano et al.'s study, which found significantly increased behavioral response compared with that of the control group. In the FSL rats, dramatically elevated KCC2 expression, especially in their cerebellum, was revealed via Western blotting and immunohistochemical data. These data suggest that spontaneous depression in animals is associated with amplified GABAergic transmission in the CNS as a result of enhanced KCC2 expression [55]. Similarly, glutamate and its receptors have an important function in pain and its chronification as well. Increased sensitivity to pain may be due to the absence of a GABAergic region in the spinal cord, especially in the dorsal horn [40].

In conclusion, neuroplasticity crucially affects the occurrence and development of chronic pain and depression and may involve the same brain structures, neurotransmitters, and signaling pathways. Through exploring the common neuroplasticity changes of these two disorders, new targeted therapeutic drugs should be able to be developed or these disorders' common targets should be able to be identified for precise treatment of chronic pain-induced depression, which will surely contribute to the improvement of life quality and prognosis in patients suffering from these disorders.

\section{Analgesic Drugs to Treat Chronic Pain- Induced Depression}

3.1. Opioids. Opioids are the most effective drugs for treating chronic pains. By combining with the opioid receptor to relieve patients' pain, opioids have been widely applied to treat various chronic pains, such as cancer pain, nociceptive pain, and neuropathic pain.

In recent years, research into the role of opioid receptors in antidepressant therapy has been emerging, with increased concern centered around the potential of opioids in antidepressant therapy. Lots of research suggest that there are three classical types: $\mu, \delta$, and $\kappa$ receptors, all of which involve in regulating mood [56], and some potential mechanisms have been studied (Figure 1) [57-61]. The combined effect of the $\mu$ receptor agonist and $\kappa$ receptor antagonist was found to have the potential to reduce the occurrence of dysphorialike behaviors in a study by Tenore [62]. Moreover, the $\kappa$ receptor antagonist has been indicated to have a possibly antidepressant effect in Mague et al.'s animal experimental study [63].

As mentioned earlier, the occurrence and development of depression involve many neurotransmitter systems that are associated with changes in neuroplasticity. The opioid receptor may achieve antidepressant effects by regulating these neurotransmitter systems; this finding has been supported by several studies [56,64]. Systemic acute morphine injection into mice has been found to have the potential to increase the release of 5-HT in several limbic systems, such as the nucleus accumbens and dorsal striatum. Thus, the finding that the $\mu$ receptor can achieve an antidepressant effect by controlling the activity of 5-HT neurons is laterally supported [61]. The $\kappa$ receptor is expressed in the nucleus accumbens presynaptically by DA neurons. It can relieve emotions by directly 
inhibiting the release of DA [65]. Numerous studies shows that $\delta$ receptor-knockout mice exhibit increased depressivelike behaviors, which indicates that $\delta$ receptor may become a potential antidepressant target [66-68].

Some animal experiments and clinical studies have demonstrated the effectiveness of some opioids in treating depression $[69,70]$. Buprenorphine is a partial agonist of the $\mu$ receptor and an antagonist of the $\kappa$ receptor and has a good affinity for the $\delta$ opioid receptor. Because its pharmacokinetics is not influenced by age and renal function, buprenorphine can be used for the middle-aged and the elderly who suffer from refractory depression [71]. A low dosage of buprenorphine for refractory depression in the first 3 weeks was found to significantly reduce depression severity but required long-term maintenance in clinical studies conducted by Karp et al. [70]. The role of buprenorphine in antidepressant therapy, together with samidorphan (an effective $\mu$ opioid receptor antagonist), was demonstrated via a multicenter, double-blind, and randomized clinical test by Fava et al. [72]. Tramadol is a weak nonopioid agonist of the $\mu$ receptor and displays properties of TCAs that inhibit the reuptake of 5-HT and NE. Tramadol was found to improve behaviors related to depression and anxiety caused by sciatic nerve injury in Caspani et al.'s examination of a chronic neuropathic pain mouse model [73]. This indicates that certain opioids may enhance synaptic plasticity and achieve the purpose of antidepressant therapy by adjusting neurotransmitter systems.

The potential of opioids in treating chronic pain-induced depression is established; however, application of opioids to antidepressant therapy has been controversial because of patients' severe dependence and addiction to them [74]. The long-term use of opioids has been shown to increase the risk of depression [75] and to even cause hyperalgesia, which can lead to depression [76]. By statistically analyzing the opioid treatment of pain in three independent American health systems, Scherrer et al. found that in the Veterans Health database, patients taking opioids for 31-90 days were found to be at an $18 \%$ higher risk for depression than those taking opioids for 1-30 days [77]. Additionally, depression may prolong the duration of opioid use [78]. The duration of opioid use in patients with a history of depression was found to be three times longer than that in patients without depression according to Braden et al.'s study [79]. Therefore, the extensive application of opioids for treating chronic pain-induced depression remains to be further studied and explored.

3.2. Benzodiazepines. Benzodiazepines have been demonstrated to have a certain therapeutic effect in treating chronic pains, including neuropathic pain or inflammatory pain [80]. The analgesic mechanism of the benzodiazepines may be associated with the antihyperalgesic effect of the $\mathrm{GABA}_{\mathrm{A}}$ receptor, which is a molecular target of the benzodiazepines in the spinal cord [81]. Because the $\mathrm{GABA}_{\mathrm{A}}$ receptors, including the $\alpha 1, \alpha 2, \alpha 3$, or $\alpha 5$ subunit, have also been found to be involved in mood regulation [82], the benzodiazepines have a potential in antidepressant therapy. By studying the $\mathrm{GABA}_{\mathrm{A}}$ receptor $\alpha 2$ subtype homozygous gene-knockout mouse, anxiety and depression-like behaviors of the mouse were markedly increased in the conflict-based noveltyinhibited feeding test and increased in despair-based forced swim test and tail suspension tests in a study by Vollenweider et al. [83]. This result suggests that the benzodiazepines can potentially treat chronic pain-induced depression.

\section{Antidepressant Drugs for Treating Chronic Pain-Induced Depression}

4.1. Monoamine Oxidase Inhibitor. Monoamine oxidase (MAO) is an important enzyme in the biogenic amine degradation pathway. MAO can be classified into two types: the type A MAO degrades $\mathrm{NE}$ and 5-HT and the type B MAO degrades phenylethylamine and benzydamine [84]; however, evidence suggests that type A MAO is more often implicated in mental disorders, including major depressive disorder [85]. Because clinical depression is associated with a decreased system of NE and/or 5-HT content in some regions of the CNS, the antidepressant effect of the classical monoamine oxidase inhibitor (MAOI) might be related to its ability to increase the NE and/or 5-HT levels of these sites $[21,85]$. The mechanism of the classical MAOI is irreversible inhibition of MAO by covalent binding to the active site of the enzyme, but it is nonspecific and can inhibit the liver microsomal enzyme system, which affects the metabolism of many drugs. In addition, some classic MAOI themselves have hepatotoxicity [86], so they are clinically no longer used for treating depression at present. In recent years, the MAOI has been represented by moclobemide, which selectively reversibly inhibits type $\mathrm{A} \mathrm{MAO}$ and has been attracting attention again due to its side effects. This drug can increase NE, 5-HT, and DA levels in the tissues, which has been confirmed by in vitro and in vivo tests [87]. Its antidepressant effect on the elderly has also been verified by clinical studies [88]. The effect of such drugs on pain treatment has been also confirmed in other clinical studies [89]. Mattia and Coluzzi found that indantadol as an oral and nonselective monoamine oxidase inhibitor and NMDA antagonist had the potential to treat neuropathic pain due to its antihyperalgesic activity [90]. However, the application of monoamine oxidase inhibitors in the treatment of chronic pain-induced depression still requires confirmation through a large number of clinical trials and animal experiments.

4.2. Tricyclic Antidepressant Drugs. Tricyclic antidepressant drugs are traditional antidepressant drugs, commonly including amitriptyline, imipramine, nortriptyline, and desipramine. The action mechanism of tricyclic antidepressant drugs may be to first inhibit 5-HT and NE reuptake at the synapse site and then enhance endogenous pain inhibition of the CNS. They are helpful for easing many chronic pains, especially neuropathic pain [91]. Because similar neuroplasticity changes occur during the experience of pain and depression in the monoamine neurotransmitter system, studies focused on the application of tricyclic antidepressant drugs in pain management have emerged unceasingly in recent years. For example, a clinical study by Kopsky and Hesselink indicated that local high doses of amitriptyline 


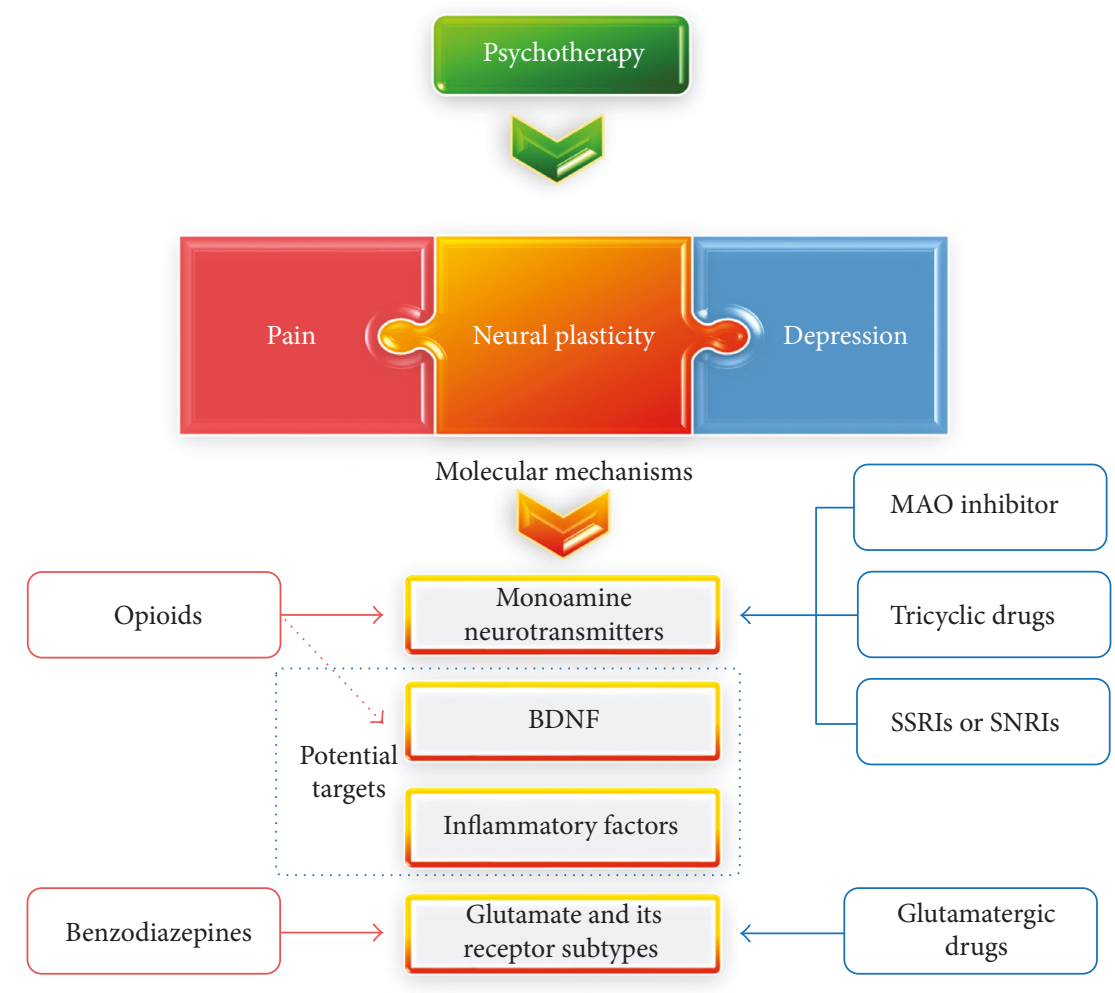

FIgURE 2: The treatment of chronic pain-induced depression.

were effective for treating neuropathic pain [92]. Furthermore, Rowbotham and colleagues, through a clinical trial of 47 neuropathic pain patients comparing three antidepressants, that is, desipramine, amitriptyline, and fluoxetine, confirmed that all three drugs can reduce pain experienced by postherpetic neuralgia patients, and the tricyclics desipramine and amitriptyline were well tolerated and provided more meaningful pain relief in $53 \%-80 \%$ of all subjects [93].

4.3. Monoamine Reuptake Inhibitors. For monoamine neurotransmitters, neurotransmitter reuptake is one of the most important determinants of signal kinetics and regulation of neurotransmitter reuptake also helps regulate the activity of the nervous network across the CNS, thus achieving an antidepressant effect [94]. With more in-depth studies on the treatment mechanism of monoamine neurotransmitters in antidepression and pain relief, inhibitors including selective 5-HT reuptake inhibitors (SSRIs) and 5-HT and NE reuptake inhibitors (SNRIs) have emerged unceasingly and have gradually become first-line drugs for clinical antidepressant therapy [95]. Antidepressant pharmacological mechanisms of SSRIs and SNRIs are to selectively act on some 5-HT and/ or NE receptor subtypes and block their reuptake to increase 5-HT and/or NE that are available for biological uses in the synaptic cleft of nerve cells, thus further enhancing monoamine neurotransmission and having an antidepressant effect. The 5-HT and NE reuptake inhibitor antidepressants have been confirmed by numerous studies to be efficacious in chronic neuropathic pain patients [96-98]. Furthermore, average pain relief (recorded via a diary) and maximum pain intensity (retrospective assessment via a computer program) in patients with chronic neuropathic pain were found to be significantly lower with antidepressant venlafaxine, a 5-HT and SNRI, compared with a placebo in Tasmuth et al.'s randomized, double-blind study [99].

4.4. Glutamatergic Antidepressant Drugs. As mentioned previously, studies have demonstrated the role of glutamate and its NMDA receptor subtypes in analgesia and antidepressant therapy [100-104]. As a noncompetitive NMDA receptor antagonist, ketamine has been used for anaesthetization since the 1960s and was reported in 2000 to rapidly improve depressive symptoms, including refractory depression within several hours. It has become a new type of antidepressant drug for targeting the glutamatergic system [105]. More importantly, studies have found that ketamine not only increased the number of synaptic connections in the PFC but rapidly improved deficits caused by chronic stress [106, 107]. Furthermore, by antagonizing the glutamatergic NMDA receptor, ketamine was found to accelerate the release of presynaptic glutamate, thereby enhancing the regional activity of the excitatory network, and eventually leading to a significant change in synaptic plasticity and connectivity $[108,109]$. This achieves the purpose of analgesia and antidepressant therapy [107]. However, such drugs have side effects such as dizziness, blurred vision, headache, nausea or vomiting, dry mouth, poor coordination, and restlessness [110]. Therefore, the safety and efficacy of ketamine and other NMDA receptor antagonists for 
treating chronic pain-induced depression remain to be further explored.

4.5. Potential Therapy Methods. Although we have summarized clinical drugs that may be therapeutically applied to treat chronic pain-induced depression, their selection for use in therapy is currently still limited. Based on our summary of common neuroplasticity changes in pain and depression, many new therapy targets may provide new future therapy directions for treating chronic pain-induced depression.

The fact that dopaminergic drugs, such as pramipexole, are effective drugs for depression inhibition suggests that enhancing DA function may form at least a partial basis for treatment response of MDD [111]. A change in the function of the DA system in the midbrain margin and the fact that certain antidepressant drugs also had a function in enhancing DA transmission have been demonstrated in studies with rodent depression models $[112,113]$. Furthermore, treatment methods for chronic depression including electroconvulsive stimulation, sleep deprivation, and almost all antidepressant drugs have been shown to enhance the role of the DA receptor agonist in motion stimulation [111]. Additionally, data and gene-related animal model studies concluded that DA could relieve pain via the D2 receptor [26]. Also supporting the claim that DA has an analgesic effect, some human studies found an increase in emotional pain rating after DA was exhausted and an improvement in conditional pain after the D2 receptor was activated $[114,115]$. Thus, the $\mathrm{D} 2$ receptor may serve as a new therapeutic target for chronic pain-induced depression.

The activity-dependent regulation expressed by the early BDNF is associated with neuronal plasticity [31]. The BDNF level of patients with depression has been found to be significantly reduced in several studies [116, 117]. Additionally, a reduced $\mathrm{BDNF}$ receptor TrkB level in the brain has also been reported [118]. Activation and phosphorylation of TrkB are also known to be significantly reduced in suicide victims $[119,120]$. Furthermore, a decrease in BDNF level can lead to a decrease in hippocampal volume and number of nerves, dendritic reconstruction, loss of glial cells, increasing neurotoxicity, and increasing susceptibility to depression [121]. Meanwhile, the BDNF has been shown to be a crucial signal molecule between microglia and neurons, which is an essential link in neuropathic pain transmission, and blocking this pathway may represent a therapeutic strategy for treating neuropathic pain [122]. Therefore, the BDNF could become a new target for treating chronic pain-induced depression in the near future.

4.6. Adjuvant Psychotherapy. In addition to the neural plasticity mechanism described above, psychosocial factors also have a significant effect on the occurrence and development of chronic pain-induced depression [123, 124]. Therefore, appropriate adjuvant psychotherapy also has a crucial role in treating chronic pain-induced depression, which has been confirmed in many clinical investigations [125-127]. For example, by means of randomized clinical trials of 342 patients with chronic back pain between 20 and 70 years of age, the group that received cognitive behavioral therapy versus usual care showed greater improvement in function (adjusted mean difference in range) [128]. Furthermore, Eccleston et al., through a retrospective analysis of 37 clinical randomized trials, found that, for children and adolescents with headache, psychological therapy decreased treatment pain and follow-up pain [129]. Thus, psychotherapy contributes to the relief from clinical symptoms, shortens the duration of the recovery cycle, improves patients' prognosis, and is recommended as a necessary adjuvant therapy for chronic pain-induced depression.

\section{Summary and Prospects}

In conclusion, pain and depression are closely correlated from the perspectives of both brain regions and the neurological function system, whereby chronic pain may lead to depression. One of the important causes for chronic pain leading to depression appears to be the crucial effect of common neuroplasticity changes on the occurrence and development of the two disorders in question (Figure 2). Nevertheless, current efforts in this field fail to sufficiently and explicitly explain their connection. Further investigations into the common neuroplasticity changes shared by pain and depression are warranted to promote the identification of new drug targets and to free patients from chronic pain-induced depression.

\section{Conflicts of Interest}

The authors confirm no conflicts of interest regarding the publication of this article.

\section{Acknowledgments}

This work was supported by grants from the Natural Science Foundation of China (NSFC: 31471120, 31540076, and 31171123).

\section{References}

[1] X. Li and L. Hu, "The role of stress regulation on neural plasticity in pain chronification," Neural Plasticity, vol. 2016, Article ID 6402942, 9 pages, 2016.

[2] R. D. Treede, W. Rief, A. Barke et al., "A classification of chronic pain for ICD-11,” Pain, vol. 156, no. 6, pp. 10031007, 2015.

[3] X. Y. Li, Y. Wan, S. J. Tang, Y. Guan, F. Wei, and D. Ma, "Maladaptive plasticity and neuropathic pain," Neural Plasticity, vol. 2016, Article ID 4842159, 2 pages, 2016.

[4] S. P. Cohen and J. Mao, "Neuropathic pain: mechanisms and their clinical implications," BMJ, vol. 348, p. f7656, 2014.

[5] H. Breivik, B. Collett, V. Ventafridda, R. Cohen, and D. Gallacher, "Survey of chronic pain in Europe: prevalence, impact on daily life, and treatment," European Journal of Pain, vol. 10, no. 4, pp. 287-333, 2006.

[6] H. A. Whiteford, L. Degenhardt, J. Rehm et al., "Global burden of disease attributable to mental and substance use disorders: findings from the Global Burden of 
Disease Study 2010," Lancet, vol. 382, no. 9904, pp. 15751586, 2013.

[7] P. Y. Collins, V. Patel, S. S. Joestl et al., "Grand challenges in global mental health," Nature, vol. 475, no. 7354, pp. 27-30, 2011.

[8] L. von Knorring, C. Perris, M. Eisemann, U. Eriksson, and H. Perris, "Pain as a symptom in depressive disorders. II. Relationship to personality traits as assessed by means of KSP," Pain, vol. 17, no. 4, pp. 377-384, 1983.

[9] P. Lee, M. Zhang, J. P. Hong et al., "Frequency of painful physical symptoms with major depressive disorder in Asia: relationship with disease severity and quality of life," The Journal of Clinical Psychiatry, vol. 70, no. 1, pp. 83-91, 2009.

[10] L. Aguera-Ortiz, I. Failde, J. A. Mico, J. Cervilla, and J. J. Lopez-Ibor, "Pain as a symptom of depression: prevalence and clinical correlates in patients attending psychiatric clinics," Journal of Affective Disorders, vol. 130, no. 1-2, pp. 106-112, 2011.

[11] M. J. Bair, R. L. Robinson, W. Katon, and K. Kroenke, "Depression and pain comorbidity: a literature review," Archives of Internal Medicine, vol. 163, no. 20, pp. 24332445,2003

[12] L. S. Williams, W. J. Jones, J. Shen, R. L. Robinson, M. Weinberger, and K. Kroenke, "Prevalence and impact of depression and pain in neurology outpatients," Journal of Neurology, Neurosurgery, and Psychiatry, vol. 74, no. 11, pp. 1587-1589, 2003.

[13] D. A. Fishbain, R. Cutler, H. L. Rosomoff, and R. S. Rosomoff, "Chronic pain-associated depression: antecedent or consequence of chronic pain? A review," The Clinical Journal of Pain, vol. 13, no. 2, pp. 116-137, 1997.

[14] E. L. Meerwijk, J. M. Ford, and S. J. Weiss, "Brain regions associated with psychological pain: implications for a neural network and its relationship to physical pain," Brain Imaging and Behavior, vol. 7, no. 1, pp. 1-14, 2013.

[15] G. M. MacQueen, K. Yucel, V. H. Taylor, K. Macdonald, and R. Joffe, "Posterior hippocampal volumes are associated with remission rates in patients with major depressive disorder," Biological Psychiatry, vol. 64, no. 10, pp. 880883, 2008.

[16] P. W. Gold, R. Machado-Vieira, and M. G. Pavlatou, "Clinical and biochemical manifestations of depression: relation to the neurobiology of stress," Neural Plasticity, vol. 2015, Article ID 581976, 11 pages, 2015.

[17] S. W. Chan, C. J. Harmer, R. Norbury, U. O'Sullivan, G. M. Goodwin, and M. J. Portella, "Hippocampal volume in vulnerability and resilience to depression," Journal of Affective Disorders, vol. 189, pp. 199-202, 2016.

[18] H. J. Kang, B. Voleti, T. Hajszan et al., "Decreased expression of synapse-related genes and loss of synapses in major depressive disorder," Nature Medicine, vol. 18, no. 9, pp. 1413-1417, 2012.

[19] M. N. Baliki, B. Petre, S. Torbey et al., "Corticostriatal functional connectivity predicts transition to chronic back pain," Nature Neuroscience, vol. 15, no. 8, pp. 1117-1119, 2012.

[20] E. J. Cohen, E. Quarta, R. Bravi, A. Granato, and D. Minciacchi, "Neural plasticity and network remodeling: from concepts to pathology," Neuroscience, vol. 344, pp. 326-345, 2017.

[21] J. Haase and E. Brown, "Integrating the monoamine, neurotrophin and cytokine hypotheses of depression - a central role for the serotonin transporter?" Pharmacology \& Therapeutics, vol. 147, pp. 1-11, 2015.

[22] A. Cleare, C. M. Pariante, A. H. Young et al., "Evidence-based guidelines for treating depressive disorders with antidepressants: a revision of the 2008 British Association for Psychopharmacology guidelines," Journal of Psychopharmacology, vol. 29, no. 5, pp. 459-525, 2015.

[23] A. Cipriani, T. A. Furukawa, G. Salanti et al., "Comparative efficacy and acceptability of 12 new-generation antidepressants: a multiple-treatments meta-analysis," Lancet, vol. 373, no. 9665, pp. 746-758, 2009.

[24] U. Doboszewska, P. Wlaz, G. Nowak, M. Radziwon-Zaleska, R. Cui, and K. Mlyniec, "Zinc in the monoaminergic theory of depression: its relationship to neural plasticity," Neural Plasticity, vol. 2017, Article ID 3682752, 18 pages, 2017.

[25] M. H. Ossipov, G. O. Dussor, and F. Porreca, "Central modulation of pain," The Journal of Clinical Investigation, vol. 120, no. 11, pp. 3779-3787, 2010.

[26] A. M. Taylor, S. Becker, P. Schweinhardt, and C. Cahill, "Mesolimbic dopamine signaling in acute and chronic pain: implications for motivation, analgesia, and addiction," Pain, vol. 157, no. 6, pp. 1194-1198, 2016.

[27] M. L. Loggia, C. Berna, J. Kim et al., "Disrupted brain circuitry for pain-related reward/punishment in fibromyalgia," Arthritis \& Rhematology, vol. 66, no. 1, pp. 203-212, 2014.

[28] I. K. Martikainen, E. B. Nuechterlein, M. Pecina et al., "Chronic back pain is associated with alterations in dopamine neurotransmission in the ventral striatum," The Journal of Neuroscience, vol. 35, no. 27, pp. 9957-9965, 2015.

[29] L. A. Glantz, J. H. Gilmore, D. H. Overstreet, K. Salimi, J. A. Lieberman, and L. F. Jarskog, "Pro-apoptotic Par-4 and dopamine D2 receptor in temporal cortex in schizophrenia, bipolar disorder and major depression," Schizophrenia Research, vol. 118, no. 1-3, pp. 292-299, 2010.

[30] C. Sagheddu, S. Aroni, M. De Felice et al., "Enhanced serotonin and mesolimbic dopamine transmissions in a rat model of neuropathic pain," Neuropharmacology, vol. 97, pp. 383-393, 2015.

[31] R. B. Foltran and S. L Diaz, "BDNF isoforms: a round trip ticket between neurogenesis and serotonin?" Journal of Neurochemistry, vol. 138, no. 2, Part B, pp. 204-221, 2016.

[32] E. J. Huang and L. F. Reichardt, "Trk receptors: roles in neuronal signal transduction," Annual Review of Biochemistry, vol. 72, pp. 609-642, 2003.

[33] R. S. Duman, G. K. Aghajanian, G. Sanacora, and J. H. Krystal, "Synaptic plasticity and depression: new insights from stress and rapid-acting antidepressants," Nature Medicine, vol. 22, no. 3, pp. 238-249, 2016.

[34] V. Krishnan and E. J. Nestler, "The molecular neurobiology of depression," Nature, vol. 455, no. 7215, pp. 894-902, 2008.

[35] L. Bocchio-Chiavetto, V. Bagnardi, R. Zanardini et al., "Serum and plasma BDNF levels in major depression: a replication study and meta-analyses," The World Journal of Biological Psychiatry, vol. 11, no. 6, pp. 763-773, 2010.

[36] R. Villanueva, "Neurobiology of major depressive disorder," Neural Plasticity, vol. 2013, Article ID 873278, 7 pages, 2013.

[37] Y. Yajima, M. Narita, A. Usui et al., "Direct evidence for the involvement of brain-derived neurotrophic factor in the development of a neuropathic pain-like state in mice," Journal of Neurochemistry, vol. 93, no. 3, pp. 584-594, 2005. 
[38] S. M. Garraway and J. R. Huie, "Spinal plasticity and behavior: BDNF-induced neuromodulation in uninjured and injured spinal cord," Neural Plasticity, vol. 2016, Article ID 9857201, 19 pages, 2016.

[39] S. K. Wood, C. S. Wood, C. M. Lombard et al., "Inflammatory factors mediate vulnerability to a social stress-induced depressive-like phenotype in passive coping rats," Biological Psychiatry, vol. 78, no. 1, pp. 38-48, 2015.

[40] A. K. Walker, A. Kavelaars, C. J. Heijnen, and R. Dantzer, "Neuroinflammation and comorbidity of pain and depression," Pharmacological Reviews, vol. 66, no. 1, pp. 80-101, 2014.

[41] H. O. Kalkman and D. Feuerbach, "Antidepressant therapies inhibit inflammation and microglial M1-polarization," Pharmacology \& Therapeutics, vol. 163, pp. 82-93, 2016.

[42] L. Capuron, G. Neurauter, D. L. Musselman et al., "Interferon-alpha-induced changes in tryptophan metabolism. Relationship to depression and paroxetine treatment," Biological Psychiatry, vol. 54, no. 9, pp. 906-914, 2003.

[43] L. Capuron, A. Ravaud, and R. Dantzer, "Early depressive symptoms in cancer patients receiving interleukin 2 and/or interferon alfa-2b therapy," Journal of Clinical Oncology, vol. 18 , no. 10 , pp. $2143-2151,2000$.

[44] D. L. Musselman, D. H. Lawson, J. F. Gumnick et al., "Paroxetine for the prevention of depression induced by high-dose interferon alfa," The New England Journal of Medicine, vol. 344, no. 13, pp. 961-966, 2001.

[45] C. L. Raison, B. J. Woolwine, M. F. Demetrashvili et al., "Paroxetine for prevention of depressive symptoms induced by interferon-alpha and ribavirin for hepatitis C," Alimentary Pharmacology \& Therapeutics, vol. 25, no. 10, pp. 1163-1174, 2007.

[46] C. L. Raison, R. Dantzer, K. W. Kelley et al., "CSF concentrations of brain tryptophan and kynurenines during immune stimulation with IFN-alpha: relationship to CNS immune responses and depression," Molecular Psychiatry, vol. 15, no. 4, pp. 393-403, 2010.

[47] M. C. Wichers, G. H. Koek, G. Robaeys, R. Verkerk, S. Scharpe, and M. Maes, "IDO and interferon-alpha-induced depressive symptoms: a shift in hypothesis from tryptophan depletion to neurotoxicity," Molecular Psychiatry, vol. 10, no. 6, pp. 538-544, 2005.

[48] G. Sanacora, C. A. Zarate, J. H. Krystal, and H. K. Manji, "Targeting the glutamatergic system to develop novel, improved therapeutics for mood disorders," Nature Reviews. Drug Discovery, vol. 7, no. 5, pp. 426-437, 2008.

[49] L. Yao and Q. Zhou, "Enhancing NMDA receptor function: recent progress on allosteric modulators," Neural Plasticity, vol. 2017, Article ID 2875904, 11 pages, 2017.

[50] P. Zanos, R. Moaddel, P. J. Morris et al., "NMDAR inhibition-independent antidepressant actions of ketamine metabolites," Nature, vol. 533, no. 7604, pp. 481-486, 2016.

[51] P. Paoletti, C. Bellone, and Q. Zhou, "NMDA receptor subunit diversity: impact on receptor properties, synaptic plasticity and disease," Nature Reviews. Neuroscience, vol. 14 , no. 6, pp. 383-400, 2013.

[52] C. Nozaki, A. M. Vergnano, D. Filliol et al., "Zinc alleviates pain through high-affinity binding to the NMDA receptor NR2A subunit," Nature Neuroscience, vol. 14, no. 8, pp. 1017-1022, 2011.
[53] H. O. Kalkman, "Alterations in the expression of neuronal chloride transporters may contribute to schizophrenia," Progress in Neuro-Psychopharmacology \& Biological Psychiatry, vol. 35, no. 2, pp. 410-414, 2011.

[54] A. D. Krystal, J. Sutherland, and D. W. Hochman, "Loop diuretics have anxiolytic effects in rat models of conditioned anxiety," PloS One, vol. 7, no. 4, article e35417, 2012.

[55] F. Matrisciano, C. Nasca, G. Molinaro et al., "Enhanced expression of the neuronal $\mathrm{K}+/ \mathrm{Cl}$ - cotransporter, $\mathrm{KCC} 2$, in spontaneously depressed Flinders Sensitive Line rats," Brain Research, vol. 1325, pp. 112-120, 2010.

[56] P. E. Lutz and B. L. Kieffer, "Opioid receptors: distinct roles in mood disorders," Trends in Neurosciences, vol. 36, no. 3, pp. 195-206, 2013.

[57] E. M. Richards, D. C. Mathews, D. A. Luckenbaugh et al., "A randomized, placebo-controlled pilot trial of the delta opioid receptor agonist AZD2327 in anxious depression," Psychopharmacology, vol. 233, no. 6, pp. 1119-1130, 2016.

[58] R. Tao and S. B. Auerbach, "GABAergic and glutamatergic afferents in the dorsal raphe nucleus mediate morphineinduced increases in serotonin efflux in the rat central nervous system," The Journal of Pharmacology and Experimental Therapeutics, vol. 303, no. 2, pp. 704-710, 2002.

[59] A. Dhir, "Investigational drugs for treating major depressive disorder," Expert Opinion on Investigational Drugs, vol. 26, no. 1, pp. 9-24, 2017.

[60] A. Saitoh and M. Yamada, "Antidepressant-like effects of delta opioid receptor agonists in animal models," Current Neuropharmacology, vol. 10, no. 3, pp. 231-238, 2012.

[61] P. Fadda, M. Scherma, A. Fresu, M. Collu, and W. Fratta, "Dopamine and serotonin release in dorsal striatum and nucleus accumbens is differentially modulated by morphine in DBA/2J and C57BL/6J mice," Synapse, vol. 56, no. 1, pp. 29-38, 2005.

[62] P. L. Tenore, "Psychotherapeutic benefits of opioid agonist therapy," Journal of Addictive Diseases, vol. 27, no. 3, pp. 49-65, 2008.

[63] S. D. Mague, A. M. Pliakas, M. S. Todtenkopf et al., "Antidepressant-like effects of kappa-opioid receptor antagonists in the forced swim test in rats," The Journal of Pharmacology and Experimental Therapeutics, vol. 305, no. 1, pp. 323-330, 2003.

[64] E. Berrocoso, P. Sanchez-Blazquez, J. Garzon, and J. A. Mico, "Opiates as antidepressants," Current Pharmaceutical Design, vol. 15, no. 14, pp. 1612-1622, 2009.

[65] A. L. Svingos, C. Chavkin, E. E. Colago, and V. M. Pickel, "Major coexpression of kappa-opioid receptors and the dopamine transporter in nucleus accumbens axonal profiles," Synapse, vol. 42, no. 3, pp. 185-192, 2001.

[66] D. Filliol, S. Ghozland, J. Chluba et al., "Mice deficient for delta- and mu-opioid receptors exhibit opposing alterations of emotional responses," Nature Genetics, vol. 25, no. 2, pp. 195-200, 2000.

[67] M. Konig, A. M. Zimmer, H. Steiner et al., "Pain responses, anxiety and aggression in mice deficient in pre-proenkephalin," Nature, vol. 383, no. 6600, pp. 535-538, 1996.

[68] A. Ragnauth, A. Schuller, M. Morgan et al., "Female preproenkephalin-knockout mice display altered emotional responses," Proceedings of the National Academy of Sciences of the United States of America, vol. 98, no. 4, pp. 19581963, 2001. 
[69] R. P. Garay, C. A. Zarate Jr., T. Charpeaud et al., "Investigational drugs in recent clinical trials for treatment-resistant depression," Expert Review of Neurotherapeutics, vol. 17, no. 6, pp. 593-609, 2017.

[70] J. F. Karp, M. A. Butters, A. E. Begley et al., "Safety, tolerability, and clinical effect of low-dose buprenorphine for treatment-resistant depression in midlife and older adults," The Journal of Clinical Psychiatry, vol. 75, no. 8, pp. e785-e793, 2014.

[71] J. Pergolizzi, R. H. Boger, K. Budd et al., "Opioids and the management of chronic severe pain in the elderly: consensus statement of an International Expert Panel with focus on the six clinically most often used World Health Organization Step III opioids (buprenorphine, fentanyl, hydromorphone, methadone, morphine, oxycodone)," Pain Practice, vol. 8, no. 4, pp. 287-313, 2008.

[72] M. Fava, A. Memisoglu, M. E. Thase et al., "Opioid modulation with buprenorphine/samidorphan as adjunctive treatment for inadequate response to antidepressants: a randomized double-blind placebo-controlled trial," The American Journal of Psychiatry, vol. 173, no. 5, pp. 499-508, 2016.

[73] O. Caspani, M. C. Reitz, A. Ceci, A. Kremer, and R. D. Treede, "Tramadol reduces anxiety-related and depression-associated behaviors presumably induced by pain in the chronic constriction injury model of neuropathic pain in rats," Pharmacology, Biochemistry, and Behavior, vol. 124, pp. 290-296, 2014.

[74] E. Ehrich, Y. Turncliff, Y. DU et al., "Evaluation of opioid modulation in major depressive disorder," Neuropsychopharmacology, vol. 40, no. 6, pp. 1448-1455, 2015.

[75] J. Salas, J. F. Scherrer, F. D. Schneider et al., "New-onset depression following stable, slow, and rapid rate of prescription opioid dose escalation," Pain, vol. 158, no. 2, pp. 306-312, 2017.

[76] L. J. Crofford, "Adverse effects of chronic opioid therapy for chronic musculoskeletal pain," Nature Reviews Rheumatology, vol. 6, no. 4, pp. 191-197, 2010.

[77] J. F. Scherrer, J. Salas, L. A. Copeland et al., "Prescription opioid duration, dose, and increased risk of depression in 3 large patient populations," Annals of Family Medicine, vol. 14, no. 1, pp. 54-62, 2016.

[78] M. D. Sullivan, "Why does depression promote long-term opioid use?” Pain, vol. 157, no. 11, pp. 2395-2396, 2016.

[79] J. B. Braden, M. D. Sullivan, G. T. Ray et al., “Trends in longterm opioid therapy for noncancer pain among persons with a history of depression," General Hospital Psychiatry, vol. 31, no. 6, pp. 564-570, 2009.

[80] J. L. Cunningham, J. R. Craner, M. M. Evans, and W. M. Hooten, "Benzodiazepine use in patients with chronic pain in an interdisciplinary pain rehabilitation program," Journal of Pain Research, vol. 10, pp. 311-317, 2017.

[81] H. U. Zeilhofer, H. Mohler, and A. Di Lio, "GABAergic analgesia: new insights from mutant mice and subtypeselective agonists," Trends in Pharmacological Sciences, vol. 30, no. 8, pp. 397-402, 2009.

[82] U. Rudolph and F. Knoflach, "Beyond classical benzodiazepines: novel therapeutic potential of GABAA receptor subtypes," Nature Reviews. Drug Discovery, vol. 10, no. 9, pp. 685-697, 2011.

[83] I. Vollenweider, K. S. Smith, R. Keist, and U. Rudolph, “Antidepressant-like properties of alpha2-containing GABA(A) receptors," Behavioural Brain Research, vol. 217, no. 1, pp. 77-80, 2011.
[84] M. Mladenovic, A. Patsilinakos, A. Pirolli, M. Sabatino, and R. Ragno, "Understanding the molecular determinant of reversible human monoamine oxidase B inhibitors containing $2 \mathrm{H}$ chromen-2-one core: structure-based and ligand-based derived 3-D QSAR predictive models," Journal of Chemical Information and Modeling, vol. 57, no. 4, pp. 787-814, 2017.

[85] M. B. Youdim, D. Edmondson, and K. F. Tipton, "The therapeutic potential of monoamine oxidase inhibitors," Nature Reviews. Neuroscience, vol. 7, no. 4, pp. 295-309, 2006.

[86] S. Zisook, "A clinical overview of monoamine oxidase inhibitors," Psychosomatics, vol. 26, no. 3, pp. 240-246, 1985, 251.

[87] M. Da Prada, R. Kettler, H. H. Keller et al., "From moclobemide to Ro 19-6327 and Ro 41-1049: the development of a new class of reversible, selective MAO-A and MAO-B inhibitors," Journal of Neural Transmission. Supplementum, vol. 29, pp. 279-292, 1990.

[88] P. Gareri, U. Falconi, P. De Fazio, and G. De Sarro, "Conventional and new antidepressant drugs in the elderly," Progress in Neurobiology, vol. 61, no. 4, pp. 353-396, 2000.

[89] D. B. Menkes, J. P. Fawcett, A. F. Busch, and D. Jones, "Moclobemide in chronic neuropathic pain: preliminary case reports," The Clinical Journal of Pain, vol. 11, no. 2, pp. 134138, 1995.

[90] C. Mattia and F. Coluzzi, "Indantadol, a novel NMDA antagonist and nonselective MAO inhibitor for the potential treatment of neuropathic pain," IDrugs, vol. 10, no. 9, pp. 636-644, 2007.

[91] M. Kremer, E. Salvat, A. Muller, I. Yalcin, and M. Barrot, "Antidepressants and gabapentinoids in neuropathic pain: mechanistic insights," Neuroscience, vol. 338, pp. 183-206, 2016.

[92] D. J. Kopsky and J. M. Hesselink, "High doses of topical amitriptyline in neuropathic pain: two cases and literature review," Pain Practice, vol. 12, no. 2, pp. 148-153, 2012.

[93] M. C. Rowbotham, L. A. Reisner, P. S. Davies, and H. L. Fields, "Treatment response in antidepressant-naive postherpetic neuralgia patients: double-blind, randomized trial," The Journal of Pain, vol. 6, no. 11, pp. 741-746, 2005.

[94] E. Castren, "Is mood chemistry?" Nature Reviews. Neuroscience, vol. 6, no. 3, pp. 241-246, 2005.

[95] E. Dale, B. Bang-Andersen, and C. Sanchez, "Emerging mechanisms and treatments for depression beyond SSRIs and SNRIs," Biochemical Pharmacology, vol. 95, no. 2, pp. 81-97, 2015.

[96] S. Gebhardt, M. Heinzel-Gutenbrunner, and U. Konig, "Pain relief in depressive disorders: a meta-analysis of the effects of antidepressants," Journal of Clinical Psychopharmacology, vol. 36, no. 6, pp. 658-668, 2016.

[97] J. Jaracz, K. Gattner, K. Jaracz, and K. Gorna, "Unexplained painful physical symptoms in patients with major depressive disorder: prevalence, pathophysiology and management," CNS Drugs, vol. 30, no. 4, pp. 293-304, 2016.

[98] R. Baron, A. Binder, and G. Wasner, "Neuropathic pain: diagnosis, pathophysiological mechanisms, and treatment," Lancet Neurology, vol. 9, no. 8, pp. 807-819, 2010.

[99] T. Tasmuth, B. Hartel, and E. Kalso, "Venlafaxine in neuropathic pain following treatment of breast cancer," European Journal of Pain, vol. 6, no. 1, pp. 17-24, 2002.

[100] G. Nowak, G. A. Ordway, and I. A. Paul, "Alterations in the $\mathrm{N}$-methyl-D-aspartate (NMDA) receptor complex in the frontal cortex of suicide victims," Brain Research, vol. 675, no. 1-2, pp. 157-164, 1995. 
[101] A. L. Gray, T. M. Hyde, A. Deep-Soboslay, J. E. Kleinman, and M. S. Sodhi, "Sex differences in glutamate receptor gene expression in major depression and suicide," Molecular Psychiatry, vol. 20, no. 9, pp. 1057-1068, 2015.

[102] A. M. Feyissa, A. Chandran, C. A. Stockmeier, and B. Karolewicz, "Reduced levels of NR2A and NR2B subunits of NMDA receptor and PSD-95 in the prefrontal cortex in major depression," Progress in Neuro-Psychopharmacology \& Biological Psychiatry, vol. 33, no. 1, pp. 70-75, 2009.

[103] T. P. Malan, H. P. Mata, and F. Porreca, "Spinal GABA(A) and $\mathrm{GABA}(\mathrm{B})$ receptor pharmacology in a rat model of neuropathic pain," Anesthesiology, vol. 96, no. 5, pp. 11611167, 2002.

[104] H. Mitani, Y. Shirayama, T. Yamada, K. Maeda, C. R. Ashby Jr., and R. Kawahara, "Correlation between plasma levels of glutamate, alanine and serine with severity of depression," Progress in Neuro-Psychopharmacology \& Biological Psychiatry, vol. 30, no. 6, pp. 1155-1158, 2006.

[105] Y. J. Huang, H. Y. Lane, and C. H. Lin, "New treatment strategies of depression: based on mechanisms related to neuroplasticity," Neural Plasticity, vol. 2017, Article ID 4605971, 11 pages, 2017.

[106] D. M. Gerhard, E. S. Wohleb, and R. S. Duman, "Emerging treatment mechanisms for depression: focus on glutamate and synaptic plasticity," Drug Discovery Today, vol. 21, no. 3, pp. 454-464, 2016.

[107] C. G. Abdallah, G. Sanacora, R. S. Duman, and J. H. Krystal, "Ketamine and rapid-acting antidepressants: a window into a new neurobiology for mood disorder therapeutics," Annual Review of Medicine, vol. 66, pp. 509-523, 2015.

[108] N. Li, B. Lee, R. J. Liu et al., "mTOR-dependent synapse formation underlies the rapid antidepressant effects of NMDA antagonists," Science, vol. 329, no. 5994, pp. 959-964, 2010.

[109] N. Li, R. J. Liu, J. M. Dwyer et al., "Glutamate N-methyl-Daspartate receptor antagonists rapidly reverse behavioral and synaptic deficits caused by chronic stress exposure," Biological Psychiatry, vol. 69, no. 8, pp. 754-761, 2011.

[110] J. W. Murrough, D. V. Iosifescu, C. L. Chang et al., "Antidepressant efficacy of ketamine in treatment-resistant major depression: a two-site randomized controlled trial," American Journal of Psychiatry, vol. 170, no. 10, pp. 1134-1142, 2013.

[111] B. W. Dunlop and C. B. Nemeroff, "The role of dopamine in the pathophysiology of depression," Archives of General Psychiatry, vol. 64, no. 3, pp. 327-337, 2007.

[112] M. F. Lazenka, K. C. Freitas, S. Henck, and S. S. Negus, "Relief of pain-depressed behavior in rats by activation of D1-like dopamine receptors," The Journal of Pharmacology and Experimental Therapeutics, vol. 362, no. 1, pp. 14-23, 2017.

[113] S. Minami, H. Satoyoshi, S. Ide, T. Inoue, M. Yoshioka, and M. Minami, "Suppression of reward-induced dopamine release in the nucleus accumbens in animal models of depression: differential responses to drug treatment," Neuroscience Letters, vol. 650, pp. 72-76, 2017.

[114] R. Treister, D. Pud, and E. Eisenberg, "The dopamine agonist apomorphine enhances conditioned pain modulation in healthy humans," Neuroscience Letters, vol. 548, pp. 115119, 2013.

[115] L. Tiemann, H. Heitmann, E. Schulz, J. Baumkotter, and M. Ploner, "Dopamine precursor depletion influences pain affect rather than pain sensation," PloS One, vol. 9, no. 4, article e96167, 2014.
[116] H. Jiang, S. Chen, C. Li et al., “The serum protein levels of the tPA-BDNF pathway are implicated in depression and antidepressant treatment," Translational Psychiatry, vol. 7, no. 4, article e1079, 2017.

[117] A. Kerling, M. Kuck, U. Tegtbur et al., "Exercise increases serum brain-derived neurotrophic factor in patients with major depressive disorder," Journal of Affective Disorders, vol. 215, pp. 152-155, 2017.

[118] E. Castren and M. Kojima, "Brain-derived neurotrophic factor in mood disorders and antidepressant treatments," Neurobiology of Disease, vol. 97, Part B, pp. 119-126, 2017.

[119] G. N. Pandey, X. Ren, H. S. Rizavi, R. R. Conley, R. C. Roberts, and Y. Dwivedi, "Brain-derived neurotrophic factor and tyrosine kinase B receptor signalling in postmortem brain of teenage suicide victims," The International Journal of Neuropsychopharmacology, vol. 11, no. 8, pp. 1047-1061, 2008.

[120] A. V. Paska, T. Zupanc, and P. Pregelj, "The role of brainderived neurotrophic factor in the pathophysiology of suicidal behavior," Psychiatria Danubina, vol. 25, Supplement 2, pp. S341-S344, 2013.

[121] R. S. Duman, "Synaptic plasticity and mood disorders," Molecular Psychiatry, vol. 7, Supplement 1, pp. S29-S34, 2002.

[122] J. A. Coull, S. Beggs, D. Boudreau et al., "BDNF from microglia causes the shift in neuronal anion gradient underlying neuropathic pain," Nature, vol. 438, no. 7070, pp. 10171021, 2005.

[123] T. K. Choi, M. J. Worley, R. S. Trim et al., "Effect of adolescent substance use and antisocial behavior on the development of early adulthood depression," Psychiatry Research, vol. 238, pp. 143-149, 2016.

[124] S. Mayor, "Community programme reduces depression in patients with chronic pain, study shows," BMJ, vol. 353, p. i3352, 2016.

[125] I. M. Goodyer, S. Reynolds, B. Barrett et al., "Cognitivebehavioural therapy and short-term psychoanalytic psychotherapy versus brief psychosocial intervention in adolescents with unipolar major depression (IMPACT): a multicentre, pragmatic, observer-blind, randomised controlled trial," Health Technology Assessment, vol. 21, no. 12, pp. 1-94, 2017.

[126] J. M. Town, A. Abbass, C. Stride, and D. Bernier, "A randomised controlled trial of intensive short-term dynamic psychotherapy for treatment resistant depression: the Halifax Depression Study," Journal of Affective Disorders, vol. 214, pp. 15-25, 2017.

[127] A. Qaseem, M. J. Barry, and D. Kansagara, "Nonpharmacologic versus pharmacologic treatment of adult patients with major depressive disorder: a clinical practice guideline from the American College of Physicians," Annals of Internal Medicine, vol. 164, no. 5, pp. 350-359, 2016.

[128] D. C. Cherkin, M. L. Anderson, K. J. Sherman et al., "Twoyear follow-up of a randomized clinical trial of mindfulness-based stress reduction vs cognitive behavioral therapy or usual care for chronic low back pain," Jama, vol. 317, no. 6, pp. 642-644, 2017.

[129] C. Eccleston, T. M. Palermo, A. C. Williams et al., "Psychological therapies for the management of chronic and recurrent pain in children and adolescents," Cochrane Database of Systematic Reviews, no. 5, p. Cd003968, 2014. 

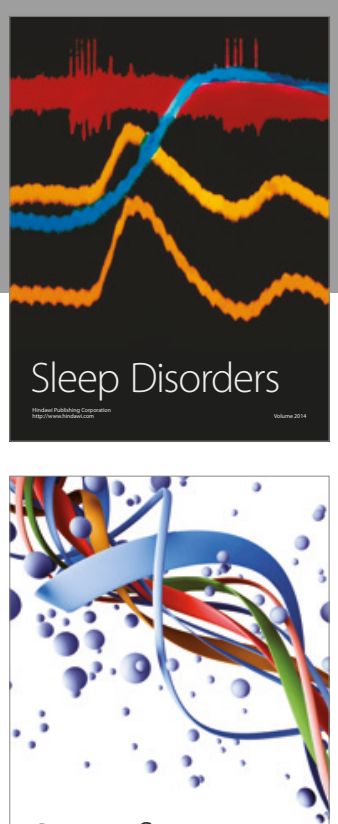

Scientifica
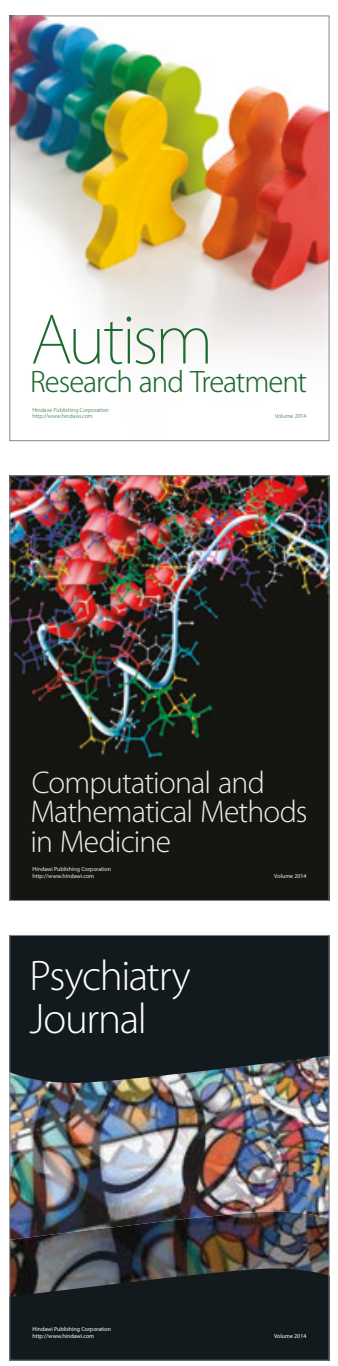
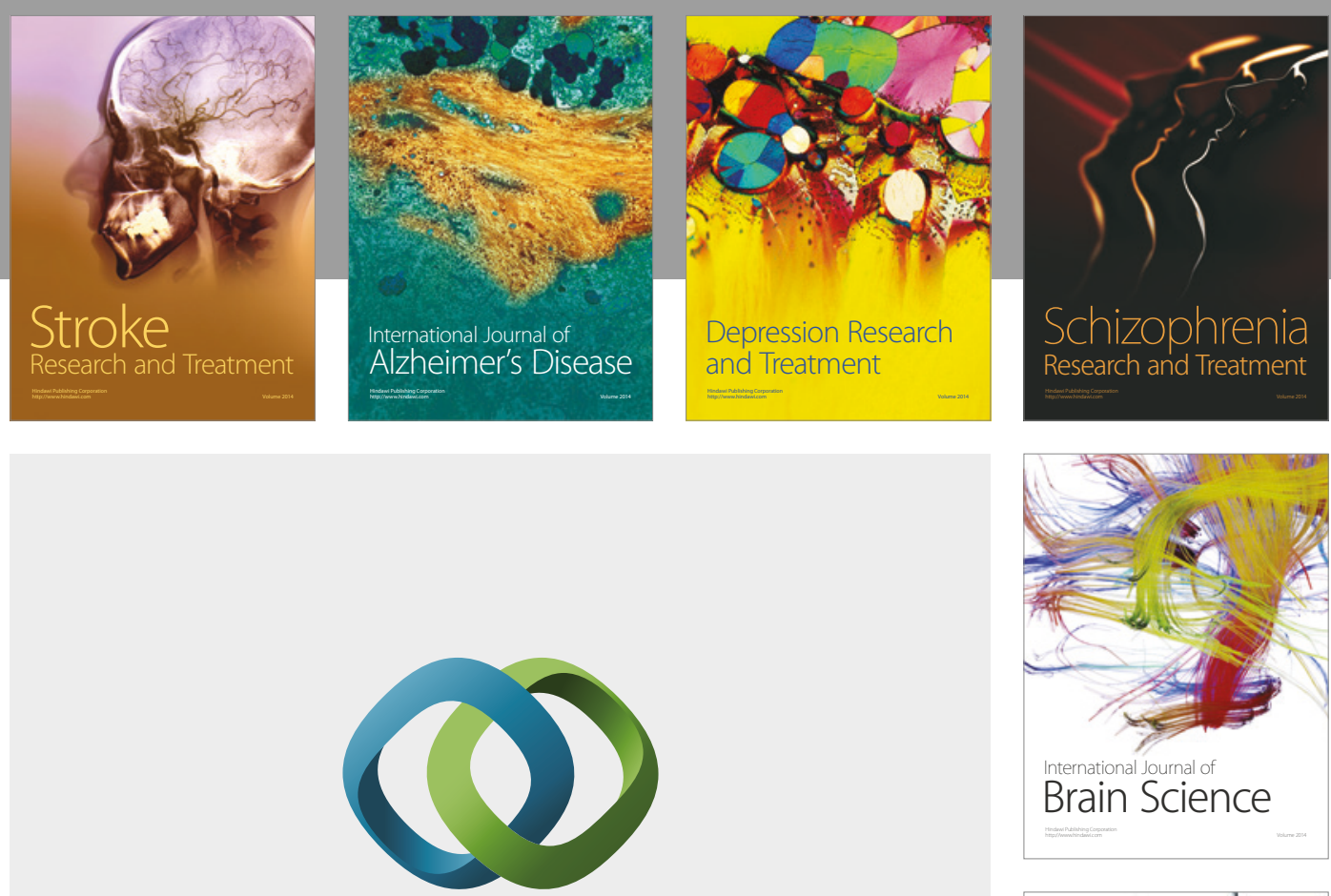

\section{Hindawi}

Submit your manuscripts at

https://www.hindawi.com
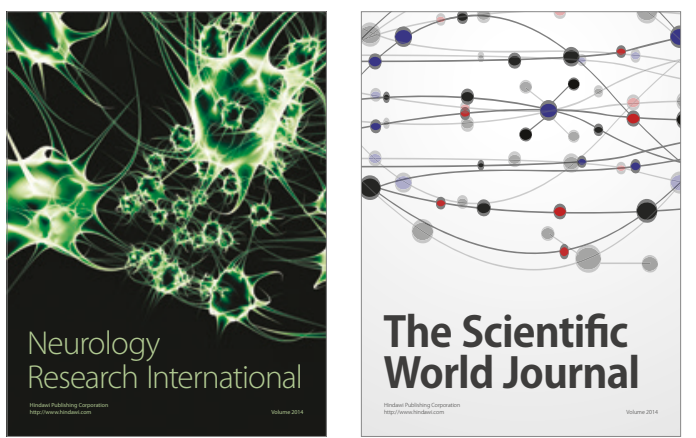

The Scientific World Journal

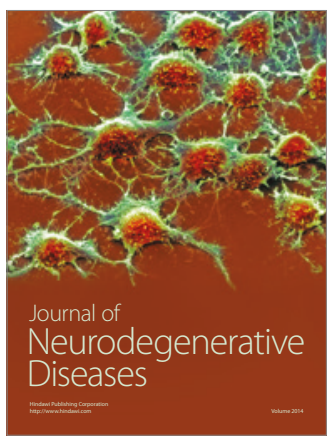

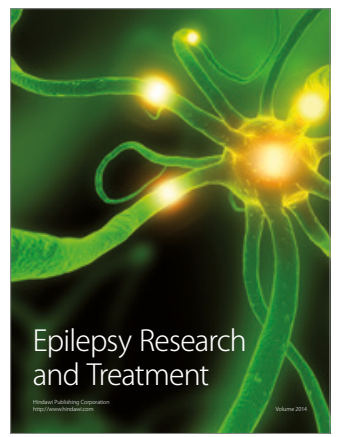

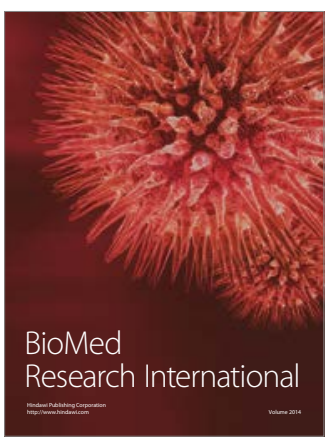

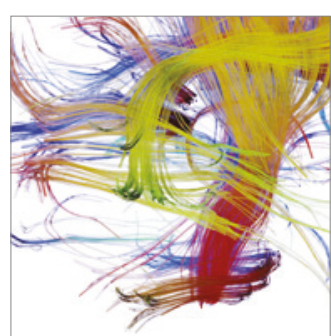

Brain Science

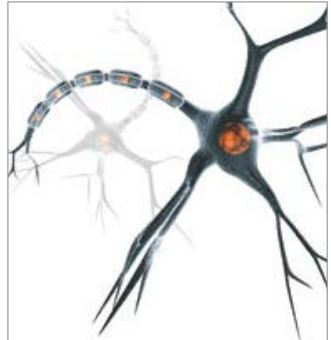

Neural Plasticity
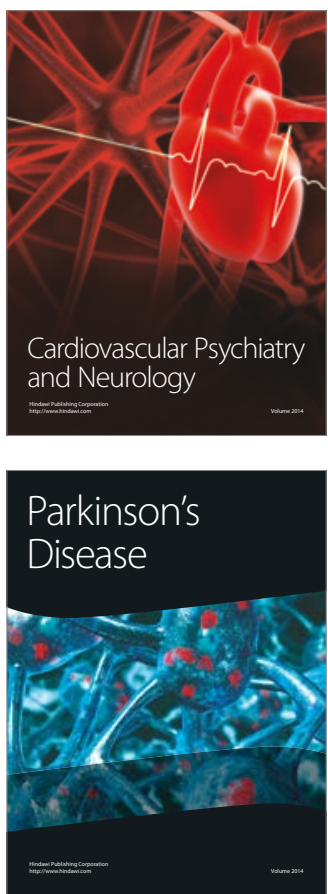